\title{
A National assessment of aichi biodiversity target 12 - an international conservation initiative
}

\begin{abstract}
The Aichi Biodiversity targets are a set of twenty targets for the Convention of Biological Diversity (CBD) that were developed with the intention to help each participating country to measure the progress made in preventing the loss of biological diversity. These targets provide a 10-year period for taking action by the countries. These targets setup in 2010 are expected to be achieved within 2020 by all the 193 countries signatory to CBD. Aichi Biodiversity Target 12 is considered to be one of the most important targets, which is directly or indirectly linked to all of the other 19 CBD Targets. Aichi-12 sets up the goal for each country to prevent the extinction of known threatened species and improve the conservation status of those species that are on decline. This target calls for establishment of conservation plans for species that face a high risk to extinction. Hence, it is of urgent need to understand the extinction risk posed to each of the threatened species in the country and the factors that are responsible for the population decline in species. Therefore, it is important for taking initiatives to remove/reduce those factors posing risk to the survival of species. This study presents a brief overview of the status and progress made by India towards achievement of Aichi-12.
\end{abstract}

Keywords: aichi biodiversity target, climate change, environment, convention on biological diversity
Volume 4 Issue 5 - 2019

\author{
Kirandeep K Dhami \\ Assistant Professor, Department of Botanical \& Environmental \\ Sciences, Guru Nanak Dev University, India
}

\author{
Correspondence: Dr. Kirandeep K Dhami,Assistant Professor \\ Department of Botanical \& Environmental Sciences, Guru \\ Nanak Dev University, Amritsar, Punjab, India, 143005, \\ Email kirandeepdhami@gmail.com
}

Received: September 24, 2019 | Published: October 15, 2019
Abbreviations: $\mathrm{CBD}$, convention of biological diversity; COP $10 / \mathrm{CBD}, 10^{\text {th }}$ conference of the Parties to the convention on biological diversity; NBT, National biodiversity targets; NR6, sixth National report; IUCN, International union for conservation of nature's

\section{Aichi and biodiversity conservation}

Aichi targets are those international targets setup by 193 countries to prevent habitat degradation and promote biodiversity conservation. Biodiversity Conservation, protection and preservation of a variety of species on the planet earth, is necessary for maintaining a balance in the natural ecosystem on the earth, ensuring the food security and preventing the climate change. ${ }^{1}$ The need for global conservation arose around the world when ecological degradation and loss in biological diversity began to affect the climate and disturb the ecological balance on earth. A loss of $10 \%$ or more bird species was recorded within a period of 10 years due to the destruction of forests in Central and South America. ${ }^{2}$ More extinctions are imminent in near future unless conservation initiatives are taken around the world. With the current species extinction rates that are estimated to be 100 times, or even as much as 1000 times higher than natural background rates of nearly $1 / 4^{\text {th }}$ of mammals, $1 / 3^{\text {rd }}$ of primates and amphibians, and $2 / 5^{\text {th }}$ of tortoises face a risk of extinction in the next 100 years. ${ }^{3}$ This ongoing and anticipated loss in biological diversity required initiatives at the global scale to prevent and minimize any losses as well as conserve the biological diversity, hence the convention on biological diversity (CBD) occurred and Aichi Targets were set up. Aichi biodiversity targets are those time-bound measurable twenty targets that have been set by all the 193 parties signatory to the convention on biological diversity (CBD) to address the biodiversity loss worldwide and promote conservation. This article briefly reviews the Aichi target 12 and its implementation at the national level in India. It aims to address the question of progress that has been made so far towards the achievement of target 12, specifically in India. How far we have come and how many needs to be done towards the achievement of target 12 as the deadline of achieving the target gets closer in 2020 .

\section{Aichi- a historical perspective}

Aichi targets were born as the outcome of CBD-One of the three "Rio Conventions" that emerged from the United Nations Conference on Environment and Development (also known as the Earth Summit, held in Rio de Janeiro in 1992), which has been considered as one of the most significant initiatives since 1993. To coordinate the action and prevent the extinction of species (https://www.cbd.int) on international scale, it came with the three main objectives:

a. The conservation of biological diversity

b. The sustainable use of biodiversity

c. An equitable sharing of the benefits arising out of the utilization of genetic resource.

Considering the initial failures in conservation efforts and ongoing loss of species as observed since 1993, a "Target Approach" was chosen to be adopted in 2000 by all the 193 parties signatory to the convention. Firstly, a set of 21 targets was set up to be met by 2010. In the first phase of targeted approach in 2002, a strategic plan was developed with a commitment to significantly reduce the current rate of biodiversity loss at the regional, national and global level, which was to be achieved by 2010 . This was a commitment from all governments including those not party to the CBD. Though substantial regional and local progress was made towards 21 targets to be achieved by 2010 including those related to the conservation of ecosystems, habitats and biomes, the conservation of genetic diversity 
and reducing the impacts of pollution, 2010 biodiversity targets were not met at the global scale. None of the 21 subsidiary targets from the 2010 Biodiversity Target were completely achieved. Not a single government submitted the reports to the $\mathrm{CBD}$, which could claim that the 2010 biodiversity targets were completely met at the national level. Hence, 2010 target was succeeded by the another set of targets to be achieved by 2020, named as 'Aichi Biodiversity targets' for 2011-2020.

Aichi Biodiversity Targets - a set of twenty targets were adopted as a part of the Strategic Plan for Biodiversity 2011-202, when the state of biodiversity continued to decline despite the increase in conservation efforts during the $10^{\text {th }}$ Conference of the Parties to the Convention on Biological Diversity (COP 10/CBD). This offered a more complex plan to reduce loss of species and natural habitats and safeguard ecosystem services, while also improving planning, financing, knowledge and benefits from sustainable management of the natural world. All 193 parties of the Convention on Biological Diversity (CBD) agreed to address the targets for the upcoming ten years period in $2010 .^{4-6}$ The targets were collectively termed as Aichi Targets, named after the location where the $10^{\text {th }}$ meeting was held in Aichi Prefecture, Japan. The set of twenty targets have been organized under five strategic goals to address the biodiversity loss worldwide (Table 1).

Table I Summarized description of the 20 aichi biodiversity targets, adapted from the global biodiversity outlook (20I4) and the CBD quick guides for the aichi biodiversity targets CBD. Unless otherwise noted, each target has 2020 as the end date

\section{Strategic Goal A}

Address the underlying causes of biodiversity loss by mainstreaming biodiversity across government and society

$\begin{array}{ll}\text { Target I } & \text { Make people aware about the values of biodiversity } \\ \text { Target } 2 & \text { Integrated biodiversity values in development and poverty reduction plan } \\ \text { Target } 3 & \text { Subsidies which are harmful to biodiversity and eliminate them, phase them out or reform them } \\ \text { Target } 4 & \text { Sustainable production and consumption. }\end{array}$

\section{Strategic Goal B}

Reduce the direct pressures on biodiversity and promote sustainable use

$\begin{array}{ll}\text { Target } 5 & \text { Reduce the rate of natural habitat loss and forest loss by at least } 50 \% \\ \text { Target } 6 & \text { Reduce overfishing } \\ \text { Target } 7 & \text { Implement Agriculture, aquaculture and forestry in sustainable manner } \\ \text { Target } 8 & \text { Reduce pollution and excessive use of fertilizer } \\ \text { Target } 9 & \text { Prevent invasive alien (non-native) species } \\ \text { Target } 10 & \text { Minimize the choral reflow destruction, ocean acidification }\end{array}$

\section{Strategic Goal B}

Reduce the direct pressures on biodiversity and promote sustainable use

$\begin{array}{ll}\text { Target } 5 & \text { Reduce the rate of natural habitat loss and forest loss by at least } 50 \% \\ \text { Target } 6 & \text { Reduce overfishing } \\ \text { Target } 7 & \text { Implement Agriculture, aquaculture and forestry in sustainable manner } \\ \text { Target } 8 & \text { Reduce pollution and excessive use of fertilizer } \\ \text { Target } 9 & \text { Prevent invasive alien (non-native) species } \\ \text { Target } 10 & \text { Minimize the choral reflow destruction, ocean acidification }\end{array}$

\section{Strategic Goal C}

To improve the status of biodiversity by safeguarding ecosystems, species and genetic diversity

$\begin{array}{ll}\text { Target II } & \text { Conserve terrestrial and inland water, coastal - marine areas } \\ \text { Target I2 } & \text { Prevent extinction of threatened species } \\ \text { Target I3 } & \text { Maintain genetic diversity of agro-plants, domesticated animals and minimizing genetic erosion }\end{array}$

\section{Strategic Goal D}

Enhance the benefits to all from biodiversity and ecosystem services

$\begin{array}{ll}\text { Target I4 } & \text { Safeguard ecosystems for women, tribal, and poor. } \\ \text { Target I5 } & \text { Combat desertification and restore the degraded ecosystem } \\ \text { Target I6 } & \text { Operationalizing the Nagoya Protocol on genetic resources, via national legislations }\end{array}$


Table Continues...

\section{Strategic Goal E}

Enhance implementation through participatory planning, knowledge management and capacity building

$\begin{array}{ll}\text { Target I7 } & \text { National biodiversity strategy and action plans - update for participation } \\ \text { Target I8 } & \text { Integrate the knowledge of tribal communities } \\ \text { Target 19 } & \text { sharing application of scientific and technological knowledge } \\ \text { Target 20 } & \text { Mobilizing financial resources }\end{array}$

\section{Target 12}

Among all the twenty targets, the Aichi Biodiversity Target 12 is considered to be one of the most ambitious targets for having a close connection with all other targets and a strong association with the progress of the other Aichi Targets. Aichi-12 aims to prevent the extinction risk of the threatened species in the world and to improve their conservation by 2020 .

As per the IUCN's Red List of Threatened Species, more than 19,000 species are threatened globally and the threatened list of species include those species which are classified as critically endangered, endangered or vulnerable. This target aims to prevent the extinction risk of the threatened species in the world and to improve their conservation by 2020 . Thus the target has two components:

\section{i. Preventing the extinction}

ii. Improving the conservation status of threatened species.

Preventing the extinction entails those species, which are currently threatened with a high risk of extinction. Critically endangered species are facing an extremely high risk of extinction in the wild. Of more than 19,000 species known to be threatened globally, more than 3,900 are classified as critically endangered. Preventing their extinction is the first objective of the target. The second objective of the target is to improve the conservation status of species i.e., increase in population of a species to a point where it can be categorized into a lower threat status category as per the IUCN. A species is no longer considered a threatened once it moves into a nearly threatened category. Since the target 12 requires one to establish the conservation plan for species threatened with extinction, it is important first to understand the extinction risk posed to the species. The global list of threatened species provides the basis for Target 12, to help identify species for conservation action. In addition to the provision of this data, the IUCN Species Program also works closely with the Species Survival Commission to both implement species conservation action on the ground and ex situ, and to develop and share guidance on species conservation action. In addition, there is a partnership of organizations and institutions that work together to support countries to achieve the success in species conservation.

\section{Aichi target I 2 - a brief National analysis}

India is a host to ten different biogeographically zones with a variety of physical features and climatic conditions that makes the country rich in biological diversity. India is the place of residence for over 45,000 species of plants and 91,000 species of animals. This huge diversity has made India one among the list of 17 mega diverse countries in the world. It accounts for $7-8 \%$ of all recorded species though it has only $2.4 \%$ of the land area in the world. Four of 34 globally identified biodiversity hotspots (The Himalayas, the Western Ghats, the North-East, and the Nicobar Islands) are found in India. To protect the rich biological diversity in the country, India became one of the signatories to the CBD and Aichi targets to be achieved by 2020 . Under the convention, India has developed 12 National Biodiversity targets (NBT) that are in line with 20 Aichi targets.

According to the sixth national report(NR6) submitted to the United Nations Convention on Biological Diversity (CBD), India is striving to meet its 12 National Biodiversity Targets (NBT) by the stipulated time of 2020. Though initiatives have been taken to meet the most of the national biodiversity targets including Aichi-12, however, the list of animal species from the country under the international 'red list' in the critically endangered, endangered and threatened categories is apparently increasing for at least past ten years. According to the sixth national report (NR6) submitted to the United Nations Convention on Biological Diversity (CBD), a total of 683 animal species in India made it to the International Union for Conservation of Nature's (IUCN) critically endangered, endangered and vulnerable categories in 2018. This number was smaller (646 species) in 2014 when the fifth report was submitted and even more smaller ( 413 species) in 2009 , when the fourth report was submitted. This increase in the 'red list' species indicates severe stress on biodiversity and wild habitats. Deforestation, habitat fragmentation, invasive species, pollution and climate change are the major reasons for this increasing risk of extinction to the listed species. Currently, India has over $20 \%$ of its geographical area under biodiversity conservation, which exceeds the terrestrial component of $17 \%$ of Aichi target 11 and 20 percent of corresponding NBT, relating to areas under biodiversity management.

Among the 683 species listed under the red list category in the country, some improvement has been observed in the population of a few threatened species in India. Tiger census report shows that the number of these wild tigers in India has increased from 226 in 2014 to 2967 in 2018. The population of lion has increased from 177 in 1968 to over 520 in 2015, elephants from 12,000 in 1970s to 30,000 in 2015. Similarly, one horned rhino that was on the brink of extinction has now a good population of 2400 . Having a systematic analysis of the content available to assess the nature and extent of the national implementation of the Aichi Targets, results indicate that most of the responses are aspirational, however most of the threatened species apparently continue to face the high risk to extinction in the coming years. Despite an increase in conservation efforts, the state of biodiversity appears to see no increase. This is largely happening because the pressures on biodiversity continue to increase.

\section{Conclusion}

Aichi-12 is an ambitious target for each participating country to be achieved by 2020, which is to prevent the extinction of threatened species in the country and improve the conservation status of those species, which are facing a high risk of extinction. While India appears to be on track to achieve the twelve National biodiversity targets for 2020 , biological diversity in the country is apparently yet under threat with the number of threatened species on the rise and apparently minute improvement with the status of already red-listed a few of 
threatened species. When the list of threatened species continues to increase it is somewhere clearly indicate the failure in our attempts to conserve biodiversity.

\section{Acknowledgments}

None.

\section{Funding}

None.

\section{Conflicts of interest}

The authors declared that there no conflicts of interest.

\section{References}

I. Wilson EO. Biodiversity.Washington DC: National Academy Press; 1988.
2. Simberloff D, Levin B. Predictable sequences of species loss with decreasing island area land birds in two archipelagoes. New Zealand J Ecol. 1985;8: | I-20.

3. IUCN.The IUCN red list of threatened species. 2019.

4. SCBD. Decision adopted by the conference of the Parties to the convention on biological diversity at its tenth meeting. $X / 2$. The strategic plan for biodiversity 20 II-2020 and the aichi biodiversity targets. 2010 .

5. SCBD. Progress towards the aichi biodiversity targets: an assessment of biodiversity trends, policy scenarios and key actions: global biodiversity outlook 4 (GBO-4) technical report. Montreal, Quebec, Canada:Secretariat of the Convention on Biological Diversity (CBD); 2014.

6. SCBD. Convention on biological diversity. List of parties. Convention on Biological Diversity; 2016. 